\title{
Prevalence and risk factors of Schistosoma haematobium infections among primary school children in Igbokuta Village, Ikorodu North Local Government, Lagos State.
}

\author{
Olalubi A. Oluwasogo ${ }^{1}$ and Olukunle B. Fagbemi ${ }^{2}$ \\ ${ }^{I}$ Department of Biological Sciences, College of Natural and Applied Sciences, Crawford University, Igbesa, \\ Nigeria. \\ ${ }^{2}$ Department of Veterinary Microbiology \& Parasitology, Faculty of Veterinary Medicine, University of Ibadan, \\ Nigeria.
}

\begin{abstract}
Background: Urinary Schistosomiasis (US) caused by Schistosoma haematobium constitutes a major public health problem in Nigeria. Efforts in this study were devoted to evaluate the current prevalence and associated risk factors on the intensity of disease burden.

Methods: A survey was conducted with the use of semi-structured questionnaires to collect sociodemographic and anthropometric data of the pupils. Urine samples were collected from One hundred and two (102) pupils for microscopic analysis for the detection of S.haematobium eggs.

Results: Of the 102 children (age ranges between 5-15 years) examined, prevalence of infection was (80/102) $78 \%$ of which (44/102) $43 \%$ were heavy and (36/102) $35 \%$ mild while $(22 / 102) 22 \%$ were negative $(p<0.05)$. The frequency of infection was higher among the female pupils (62/102) $61 \%$ compared to the male counterpart (40/102) $39 \%(p<0.05)$. Striking risk factors that could predispose the pupils to S.haematobium infection follows the order: swimming / drinking contaminated water $>$ washing of clothes in streams > playing / bathing in rivers $>$ unknown $>$ mosquito bites $>$ fresh water snail. No significant difference exists between the risk factors ( $p>0.05)$. The mean age, weight, height, waist circumference and hip circumference of the negative individuals (both males and females) were significantly higher than that of their positive counterpart $(p<0.05)$. There was no significant difference in the mean age, height and waist circumference of the heavy and mild infected females compared to their male counterpart ( $p>0.05)$. Similarly, there was no significant difference in the mean hip circumference of the heavy and mild infected male and female $(p>0.05)$. Correlation analysis showed that there is significant correlation between infection status and age $(r=0.385, p>0.01)$, weight $(r=$ $0.404, p>0.01)$, height $(r=0.401, p>0.01)$, waist $(r=0.396, p>0.01)$, hip circumference $(r=0.415, p>0.01)$ and risk factor ( $r=-0.231, p>0.05)$. Risk factor is not significant to age, weight, height, waist, hip circumference and infection status ( $p>0.05$ ).

Conclusion: Prevalence rate obtained in the study was high, an indication that the region is endemic by WHO classification. This calls for an urgent effective urinary schistosomiasis control programme in the zone.

Key words: Schistosoma haematobium; Prevalence; Gender; Age; Risk factors
\end{abstract}

\section{Introduction}

Schistosomiasis still remains the second most prevalent tropical parasitic disease after malaria, and a leading cause of severe morbidity in many parts of the world ${ }^{1}$. The disease is caused by the parasitic helminth of the genus Schistosoma and transmitted through fresh water snail intermediate hosts. About 200 million people worldwide are estimated to be infected with $S$. haematobium of which $70 \%$ live in sub-Saharan Africa ${ }^{2}$. Schistosomiasis is widely distributed in Nigeria. It is hyper-endemic in many states of the north and southwest with moderate to low endemicity in the southeast ${ }^{3}$. Schistosoma haematobium occurs in nearly all endemic foci while $S$. mansoni is predominantly found in the north and some part of the southwest.

Although infection with schistosomes does not always result in clinical manifestation of disease and many infections are asymptomatic ${ }^{2}$. Schistosoma haematobium infection however could cause anaemia, haematuria, dysuria, nutritional deficiencies, lesion of the bladder, kidney failure, an elevated risk of bladder cancer and in children growth retardation ${ }^{2}$. Accordingly the estimates for morbidity and mortality in affected populations are high with school age children usually presenting with the highest prevalence and intensity of infection ${ }^{2}$. Studies in Nigeria among school aged children in various parts of the country and in both rural and urban environments have shown that S. haematobium is clearly a problem of this age group. Prevalence among school aged children ranges from $20-40 \%$ in typical communities ${ }^{4,5}$, but can be as high as $50-70 \%$ in areas where environmental changes occur due to constructions such as human-made dams and quarries ${ }^{6,7}$. In Ogun and Lagos State, urinary schistosomiasis has been reported in several communities ${ }^{8-15}$. Igbokuta village is transverse by streams, ponds and rivers which constitute the major sources of water supply to all the 
communities in the environment. Village primary school children are particularly vulnerable to schistosomiasis because of their routine habit and lifestyle. Water contact recreational activities among primary school children between the ages of 5-15 years old includes bathing, swimming, drinking, washing clothes or kitchen utencils and fetching of water, are generally the norm which serves as potential source of transmission ${ }^{16}$. Systematic schistosomicidal treatment had never been applied in the village ${ }^{16}$. Infection with urinary schistosomiasis occurs very early in life through exposure to contaminated water bodies. Primary school pupils (age ranges between 515 years) were recruited and examined for the study because they are immunologically naive; hence peak of prevalence of schistosomiasis is found in this age-group.

Therefore this study was conducted to estimate the current prevalence, influence of age, and gender distribution on the intensity of the disease burden. Also, risk factors associated with Schistosoma haematobium infections among primary school children in Igbokuta village were also evaluated so as to decide on modalities for community and government intervention.

\section{Study Area and Population}

\section{Material \& Methods}

One hundred and two (102) children (age ranges between 5-15 years) were examined for the study. The study was conducted at Igbokuta Village in Ikorodu Local Government Area of Lagos State, Nigeria. The choice of the zone was based on reports from local hospitals, clinics and health centres of incessant cases of urinary schistosomiasis in the rural communities particularly among primary school children. The climate of the area is tropical and the vegetation characteristic is predominantly the rainforest with an annual average rainfall of about $1,900 \mathrm{~mm}$ and average atmospheric temperature of $28{ }^{\circ} \mathrm{C}$. There are two distinct seasons, the wet and dry seasons. The former takes place between April and October, while the later occurs from November to March. Igbokuta village population was roughly estimated at 3000 inhabitants. The villagers are predominantly peasant farmers and fishermen.

\section{Questionnaire Administration, Urine Collection and Examination of Schistosoma haematobium Ova}

Each child was administered a simple health semi-structured questionnaire to collect sociodemographic and anthropometric data of the pupils. Information on age, sex, educational background, religion, perception, knowledge of symptoms, sources of water supply / mode of transmission and health implications of schistosomiasis were obtained. The class teachers administered the questionnaire to the children in the language (Yoruba or English) he / she understand best.

Dark (black), clean, sterile plastic universal containers (labelled) were given to the class teachers of the pupils to collect urine samples. This was done between the hours of $10.00 \mathrm{am}$ to $2.00 \mathrm{pm}$. The urine collected was immediately taken to the laboratory for analysis. Samples with visible haematuria were noted. Each sample was examined for schistosome eggs using the sedimentation by gravity method ${ }^{18,20}$. A $10 \mathrm{ml}$ subsample was taken from each original sample into a pre-labelled $30 \mathrm{ml}$ universal sterillin -bottle with a conical bottom, and preserved in $40 \%$ formaldehyde. Each bottle was held upright for at least $3 \mathrm{hrs}$ to enable schistosome eggs to settle in the groove of the conical bottle. The clear supernatant was withdrawn in a $10 \mathrm{ml}$ syringe affixed with a $21 \mathrm{G}$ needle. The sediment left in the groove was mixed, measured, diluted to known volume if concentrated and $1 \mathrm{ml}$ transferred to a crosshatched counting chamber (haemocytometer). The chamber was examined under a light microscope at X 40 magnification for the presence and number of S. haematobium eggs corrected to sediment volume. Urine samples containing egg(s) of S. haematobium which is characterised with a terminal spine were recorded as positive, while absence of eggs of schistosomes was considered negative ${ }^{17}$. The eggs were counted and recorded as eggs/ $10 \mathrm{ml}$ of urine. Those positive for urinary schistosomiasis infection were treated with $40 \mathrm{mg} / \mathrm{kg}$ of praziquantel according to WHO guideline.

\section{Laboratory Analysis to Determine the Degree of Intensity of Schistosoma haematobium infection}

The urine sedimentation technique described previously ${ }^{18,19}$ was used to detect the presence of $S$. haematobium ova in the urine samples and to determine the intensity of the infection in each case. Intensity was reported as the number of ova / $10 \mathrm{ml}$ of urine and was categorized as mild ( $\leq 50$ ova / $10 \mathrm{ml}$ of urine) and heavy ( $\geq 50$ ova $/ 10 \mathrm{ml}$ of urine) ${ }^{21}$. A few drops of saponin solution were added to samples with visible haematuria to enhance clarity in microscopy ${ }^{20}$.

\section{Examination of Urine for Microhaematuria}

A reagent strip (Medi- Test Combi-9) was carefully dipped into the dark sterile bottle containing the urine for 5 seconds. The resulting change in colour of the strip was compared with manufacturer's colour chart to estimate the amount of blood in the urine. The chemical strips registered urinary blood as negatives or positives $(+,++,+++)^{35}$. 


\section{Assessment of Clinical and Nutritional Deficiencies}

Vital signs and anthropometric parameters were evaluated. Such includes body temperature, pulse rate / beat, packed cell volume (PCV), body weight, height, waist and hip circumferences. Body weight was measured to the nearest $100 \mathrm{~g}$ using battery-operated digital scales (SECA, manufactured for UNICEF). Each pupil stood erect against a stadiometer affixed to a wall for measurement of height to the nearest $0.1 \mathrm{~cm}$. Waist and hip Circumferences were measured with a flexible tape rule and recorded to $0.1 \mathrm{~cm}^{2}$.

\section{Ethical Consideration}

The study was approved by State Ministry of Health $(\mathrm{SMoH})$ followed by both the Local Health Authority and the Parent-Teachers Association (PTA) of each of the schools used for the study. The study was explained to each participant. Individuals or caregivers were asked to consent verbally to participate in the study; only those who provided consent were registered and requested to provide samples. Parents / guardians provided informed consent on behalf of all pupil participants.

\section{Statistical Analysis}

The data obtained were analyzed using Chi-Square statistics, Duncan Multiple Range Test of Analysis of variance (ANOVA) and correlation analysis. Values were expressed as mean \pm standard deviation. Differences between two different parameters were considered significant if the $\mathrm{P}$ value was less than 0.05.

\section{Results}

Generally, an age range of $\leq 8$, between 8-11 and 12-15 years occurs with the frequencies of $34 \%$, $53 \%$, and 15\% respectively (Table 1). Of the 102 children (age ranges between 5-15 years) examined, prevalence of infection was (80/102) $78 \%$ of which (44/102) $43 \%$ were heavy and (36/102) $35 \%$ mild infections while (22/102) $22 \%$ were negative $(p<0.05)$. Statistical analysis indicates a significant difference $(p<$ 0.05). Striking risk factors that could predispose the pupils to S.haematobium infection follows the order swimming / drinking contaminated water $>$ washing of clothes in streams $>$ playing / bathing in rivers $>$ unknown $>$ mosquito bites $>$ fresh water snail. No significant difference exists between the risk factors $(p>0.05)$. Pupils with body weight ranges between $25.0-29.0 \mathrm{~kg}$ occurred with frequency of $52 \%$ while the least frequency (17 $\%$ ) was recorded among those who weighed between $30.0-34.0 \mathrm{~kg}$. Chi square test indicated that there was a significant difference $(p<0.05)$ (Table1).

Table1: Prevalence, Demographic, anthropometric parameters and predisposing risk factors of Schistosoma haematobium infection.

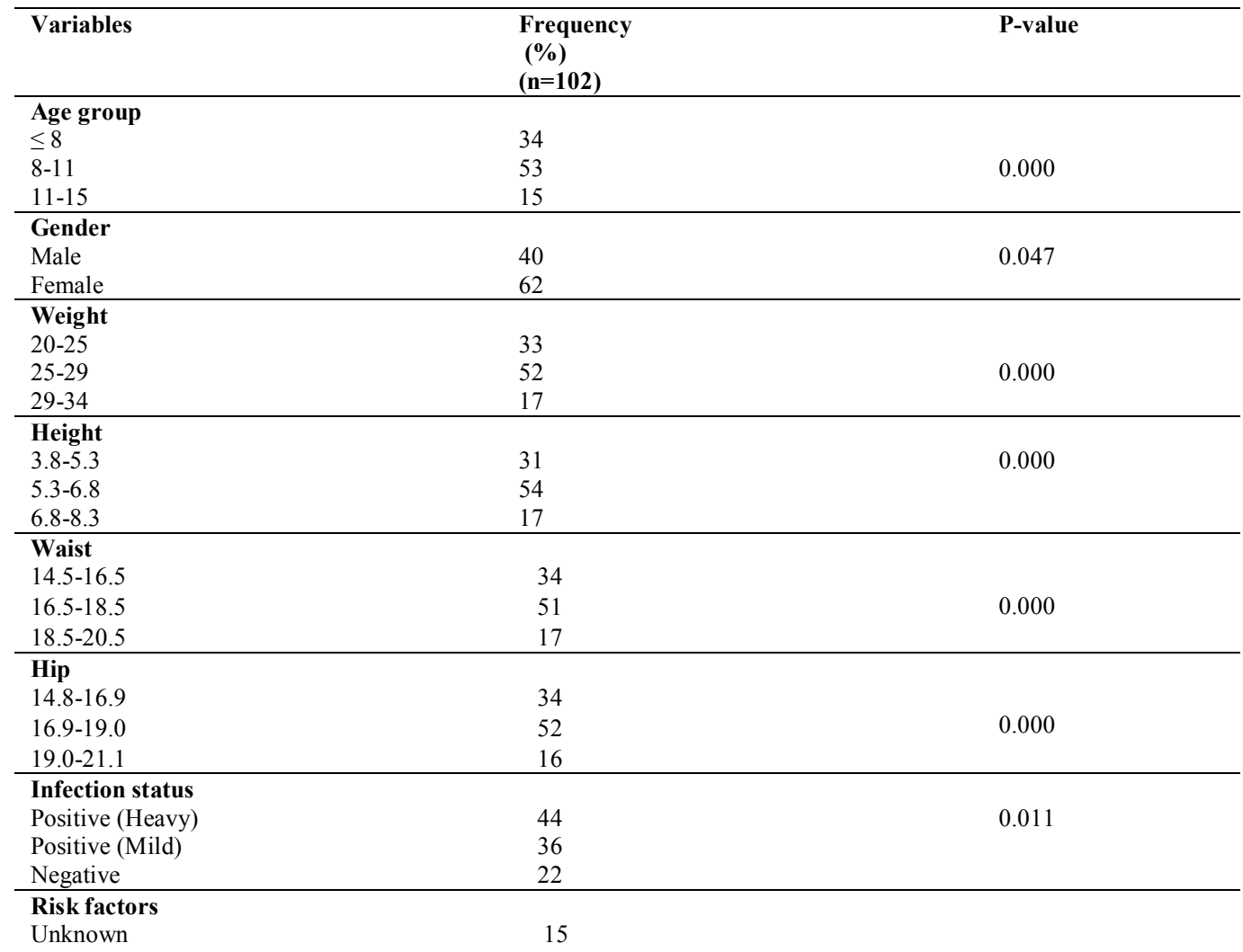




Swimming / Drinking contaminated water
Playing / bathing in river
Washing of Clothes in streams
Mosquito bite
Freshwater snail

The pattern of S. haematobium infection by intensity, gender, risk factors, age and anthropometric parameters are summarized in Table 2.The frequency of infection was higher among the female pupils (62/102) $61 \%$ compared to the male counterpart $(40 / 102) 39 \%(p<0.05)$ (Table 2$)$. Positive heavy and mild infected individuals were implicated with more of significant risk factors such as washing of clothes in streams, swimming / drinking contaminated water, playing / bathing in rivers and fresh water snail. However, the positive heavy infected male were more predisposed to risk factors such as swimming / drinking contaminated water, washing of clothes in streams and fresh water snail while the female counterpart were predisposed to swimming / drinking contaminated water, washing of clothes in streams, mosquito bites and fresh water snail. Positive mild male were more predisposed to playing / bathing in water and washing of clothes in streams compared to the female counterpart that were predisposed to swimming / drinking contaminated water, washing of clothes in streams and mosquito bites. The mean age, weight, height, waist circumference and hip circumference of the negative individuals (both males and females) were significantly higher than that of their positive counterpart $(p<0.05)$ (Table 2). There was no significant difference in the mean age, height and waist circumference of the heavy and mild infected females compared to their male counterpart $(p>0.05)$. Similarly, there was no significant difference in the mean hip circumference of the heavy and mild infected male and female $(p>0.05)$.

Table 2 : Prevalence and intensity of Schistosoma haematobium infection in relation to demographic, anthropometric parameters and risk factors.

\begin{tabular}{|c|c|c|c|c|c|c|c|c|c|c|c|c|c|c|}
\hline \multirow{2}{*}{$\begin{array}{l}\text { Infection } \\
\text { Status } \\
\text { Prevalence }\end{array}$} & & \multirow{2}{*}{\multicolumn{2}{|c|}{$\begin{array}{l}\text { Sex } \\
\text { /frequency }\end{array}$}} & \multicolumn{6}{|c|}{ Risk factors } & \multirow{2}{*}{$\begin{array}{l}\text { Mean } \\
\text { age } \\
\text { (years) }\end{array}$} & \multirow{2}{*}{$\begin{array}{l}\text { Mean } \\
\text { weight } \\
\text { (cm) }\end{array}$} & \multirow{2}{*}{$\begin{array}{l}\text { Mean } \\
\text { height } \\
(\mathrm{cm})\end{array}$} & \multirow{2}{*}{$\begin{array}{l}\text { Mean } \\
\text { Waist } \\
\text { Circumf } \\
\text { erence } \\
\text { (cm) }\end{array}$} & \multirow{2}{*}{$\begin{array}{l}\text { Mean Hip } \\
\text { Circumf } \\
\text { rence }(\mathrm{cm})\end{array}$} \\
\hline & & & & 1 & 2 & 3 & 4 & 5 & 6 & & & & & \\
\hline \multirow[t]{2}{*}{ +ve Heavy } & 44 & $\mathbf{M}$ & 19 & 1 & 5 & 2 & 4 & 2 & 5 & $\begin{array}{l}7.5 \pm 1.89 \\
\mathrm{c}\end{array}$ & $\begin{array}{l}23.8 \pm 3.6 \\
3^{\mathrm{c}}\end{array}$ & $\begin{array}{l}5.3 \pm 0.7 \\
3^{\mathrm{c}}\end{array}$ & $\begin{array}{l}16.4 \pm 1.1 \\
7^{\mathrm{c}}\end{array}$ & $17.0 \pm 0.99^{b}$ \\
\hline & & $\mathbf{F}$ & 25 & 5 & 4 & 3 & 4 & 5 & 4 & $\underset{b c}{8.7 \pm 2.05}$ & $\begin{array}{l}26.2 \pm 2.6 \\
7^{b}\end{array}$ & $\begin{array}{l}5.8 \pm 0.7 \\
4^{\text {bc }}\end{array}$ & $\begin{array}{l}17.2 \pm 1.0 \\
8^{\text {bc }}\end{array}$ & $17.4 \pm 1.09^{b}$ \\
\hline \multirow[t]{2}{*}{ +ve Mild } & 36 & $\mathbf{M}$ & 13 & 1 & 2 & 4 & 3 & 1 & 2 & $\begin{array}{l}9.4 \pm 1.90 \\
b\end{array}$ & $\begin{array}{l}26.8 \pm 2.4 \\
3^{\text {b }}\end{array}$ & $\begin{array}{l}6.0 \pm 0.7 \\
2^{\mathrm{b}}\end{array}$ & $\begin{array}{l}17.6 \pm 1.0 \\
0^{\mathrm{b}}\end{array}$ & $17.9 \pm 1.00^{\mathrm{b}}$ \\
\hline & & $\mathbf{F}$ & 23 & 3 & 8 & 1 & 7 & 3 & 1 & $\begin{array}{l}8.4 \pm 2.02 \\
b c\end{array}$ & $\begin{array}{l}25.6 \pm 2.7 \\
4^{b c}\end{array}$ & $\begin{array}{l}5.6 \pm 0.7 \\
5^{\text {bc }}\end{array}$ & $\begin{array}{l}17.0 \pm 1.1 \\
3^{\text {bc }}\end{array}$ & $17.3 \pm 1.16^{\mathrm{b}}$ \\
\hline \multirow[t]{4}{*}{$\begin{array}{l}\text {-ve } \\
\text { (Negative) }\end{array}$} & 22 & $\mathbf{M}$ & 8 & 3 & 1 & 1 & 1 & 2 & - & $\begin{array}{l}11.9 \pm 1.5 \\
5^{\mathrm{a}}\end{array}$ & $\begin{array}{l}30.4 \pm 1.9 \\
2^{\mathrm{a}}\end{array}$ & $\begin{array}{l}6.9 \pm 0.3 \\
9^{\mathrm{a}}\end{array}$ & $\begin{array}{l}18.7 \pm 0.9 \\
5^{\mathrm{a}}\end{array}$ & $19.1 \pm 0.76^{\mathrm{a}}$ \\
\hline & & $\mathbf{F}$ & 14 & - & 6 & 5 & 1 & - & - & $\begin{array}{l}11.0 \pm 2.9 \\
0^{\mathrm{a}}\end{array}$ & $\begin{array}{l}29.3 \pm 3.5 \\
0^{\mathrm{a}}\end{array}$ & $\begin{array}{l}6.6 \pm 1.1 \\
7^{\mathrm{a}}\end{array}$ & $\begin{array}{l}18.5 \pm 1.6 \\
0^{\mathrm{a}}\end{array}$ & $18.8 \pm 1.64^{\mathrm{a}}$ \\
\hline & 10 & & 10 & 1 & 1 & 1 & 2 & 1 & 1 & & & & & \\
\hline & 2 & & 2 & 3 & 6 & 6 & 0 & 3 & 2 & & & & & \\
\hline
\end{tabular}

\section{Key : Risk factors}

$1=$ Unknown

$2=$ Swimming / Drinking contaminated water

$3=$ Playing $/$ bathing in river

$4=$ Washing clothes in streams

$5=$ Mosquito bite

6=Freshwater snail

Mean \pm SD : Column having the same letter are no significantly different using Duncan Multiple Range Test of ANOVA.

The result of the correlation analysis showed that there is significant correlation between infection status and age $(\mathrm{r}=0.385, p>0.01)$, weight $(\mathrm{r}=0.404, p>0.01)$, height $(\mathrm{r}=0.401, p>0.01)$, waist $(\mathrm{r}=0.396, p>0.01)$, hip circumference $(\mathrm{r}=0.415, p>0.01)$ and risk factor $(\mathrm{r}=-0.231, p>0.05)$. Risk factor is not significant to age, weight, height, waist and hip circumference and infection status $(\mathrm{P}>0.05)$ (Table 3$)$ 
Table 3 : Correlation analysis of demographic, anthropometric parameters and risk factors of Schistosoma haematobium infection

\begin{tabular}{|c|c|c|c|c|c|c|c|c|}
\hline & Age & Weight & Height & Waist & Hip & $\begin{array}{r}\text { Risk } \\
\text { factor }\end{array}$ & Sex & $\begin{array}{l}\text { Infection } \\
\text { status }\end{array}$ \\
\hline Age & 1 & $0.989 * *$ & $0.955^{* *}$ & $0.978 * *$ & $0.978 * *$ & -0.053 & -0.037 & $0.385 * *$ \\
\hline Height & & & 1 & $0.957 * *$ & $0.957 * *$ & -0.098 & -0.074 & $0.401 * *$ \\
\hline Waist & & & & 1 & $0.979 * *$ & -0.052 & -0.036 & $0.396 * *$ \\
\hline Risk factor & & & & & & 1 & -0.116 & $-0.231 *$ \\
\hline Sex & & & & & & & 1 & 0.037 \\
\hline Infection status & & & & & & & & 1 \\
\hline
\end{tabular}

**Correlation is significant at 0.01 level (2-tailed)

* Correlation is significant at 0.05 level (2-tailed)

(37/102) $36 \%$ and (24/102) $24 \%$ of the infected children presented with haematuria and severe anemia with weight loss as pronounced clinical symptoms associated with urinary schistosomiasis. Other symptoms include supra-pubic pain and painful micturation, dry scaly skin, ricket and allergies (Table 4).

Table 4 : Clinical signs and symptoms associated with urinary schistosomiasis among primary school children in Igbokuta Village, Ikorodu North Local Government, Lagos State.

\begin{tabular}{lcc}
\hline Presenting Symptoms & Number Examined (102) & Frequency \% \\
\hline Visible haematuria & $37(\mathrm{~F}=21 ; \mathrm{M}=16)$ & 36.0 \\
Supra-pubic pain and Painful Micturation & $16(\mathrm{~F}=9 ; \mathrm{M}=7)$ & 16.0 \\
Severe Anemia and Weight loss & $24(\mathrm{~F}=15 ; \mathrm{M}=9)$ & 24.0 \\
Dry scaly skin, ricket and allergies & $14(\mathrm{~F}=8 ; \mathrm{M}=6)$ & 14.0 \\
None Observable & $11(\mathrm{~F}=7 ; \mathrm{M}=4)$ & 11.0 \\
\hline
\end{tabular}

\section{Discussion}

The result of this study demonstrated a prevalence rate of $78 \%$ of urinary schistosomiasis among primary school pupils of Igbokuta Village in Ikorodu Local Government Area of Lagos State, Nigeria. This is in close agreement with that of Ezza-North Local Governent area of Ebonyi State, South-Eastern Nigeria ${ }^{2}$.This satisfies the WHO classification as endemic ${ }^{24}$. Similar earlier studies have indicated that S.haematobium is

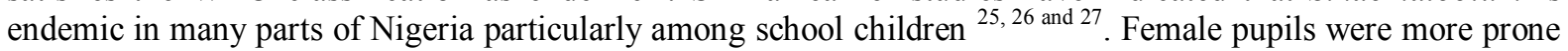
to $S$. haematobium infection compare to their male counterpart. The frequency of infection was higher among the female pupils (61\%) compared to the male counterpart (39\%) and the difference was statistically significant $(p<0.05)$ (Table 2). This may not be unconnected with the fact that females are more engaged in water related activities such as washing clothes and dishes, routine fetching of water for domestic use, bathing and cleaning ${ }^{21}$. Similar results were obtained in Nigeria by Tohon et al., ${ }^{22}$. However, this is in contrast with result obtained in the Qena governorate in Egypt where males were more infected than females ${ }^{23}$.

The higher prevalence rate of urinary schistosomiasis in this study reflects the higher level of exposure, habits, lifestyle and dependence of the inhabitants on the infected contaminated water bodies. Significant risk factors such as swimming / drinking contaminated water, washing of clothes in streams and playing / bathing in rivers have been implicated for the high intensity of urinary schistosomiasis in the community. In addition, mean age of infected pupils ranges from $7.5 \pm 1.89$ to $8.4 \pm 2.02$ and heavier among pupils of $7.5 \pm 1.89$ to $8.7 \pm$ 2.05 years (Table 2). As reported by other scholars ${ }^{28,29}$, the prevalence of urinary schistosomiasis is highest among primary school pupils in age groups 8-11 years and lowest among pupils of age range 12-15. This may be due to improved habits, low level of exposure and the development of naturally acquired anti- $S$. haematobium antibodies as age progresses ${ }^{36}$.

Obviously among the pupils, female had relatively higher frequency of infection compared to the male counterpart. This could be due to differences in exposure to the risk factors. However, there were no significant difference between risk factors and infection status of females and males $(p>0.05)$ (Table 3).

Furthermore, clear association was established between $S$. haematobium infection and the nutritional status of the pupils as depicted by the anthropometric parameters (Table1). It has been estimated that more than 230 million (43\%) of all pre-school children in the developing world are stunted in their growth because of malnutrition cause by food shortage and disease including urinary schistosomiasis ${ }^{2}$. In the light of this, anthropometric parameters were used to evaluate the nutritional status of the children in relation to body size, composition, weight which may reflect inadequate food intake and disease. Anthropometry has been described as the single most universally applicable, inexpensive, non-invasive method available to assess size, proportion, height and composition of the human body ${ }^{2}$. In the field of nutrition, low height and or weight relative to 
reference data have been used as classic indicators of under and malnutrition for individuals and groups; and recent research has expanded the applications of anthropometry to include predicting who will benefit from intervention strategies, identifying social and economic inequity, and evaluating responses to interventions ${ }^{30}$.

From this study, it is however pronounced that S. haematobium endemicity may be playing a leading role in the growth retardation of majority of the infected children in the region. A previous study in Kenya provided evidence that relatively heavy infections of $S$. haematobium could cause urinary iron loss which, if it persists, is great enough to produce iron deficient anemia and can also reduce physical fitness of children ${ }^{31}$.

Conversely, earlier study in Nigeria could not demonstrate any significant impact of urinary schistosomiasis utilizing anthropometric parameters among the infected children compared with the uninfected controls $^{2}$. This was attributed to low intensity of the infection among the children investigated ${ }^{32}$. Findings from this study therefore suggest that in an area of high endemicity of urinary schistosomiasis, the disease may affect the growth and the nutritional status of children adversely. Different species of Schistosoma have been shown to be associated with linear growth retardation in school children in many developing countries ${ }^{33,34}$, hence the need to target this population at risk for intervention. This study also revealed that haematuria coupled with severe anemia and weight losses were the most common signs and symptoms of urinary schistosomiasis in the region. Also, haematuria and severe anemia were significant among both female and male pupils investigated. Poor iron status and anemia is closely linked to diminished education performance at school ${ }^{21}$. Since schistosomiasis cause blood loss leading to iron deficiency, it is conceivable that the educational performance and achievement of infected school children will be impeded unless actions are taken to keep infection intensities absolutely low through regular deworming ${ }^{21}$. A randomized evaluation of a project in Kenya suggested that school-based mass treatment with deworming drug reduced school absenteeism in treatment schools by $25 \%^{21}$.

\section{Conclusion}

Prevalence rate of urinary schistosomiasis obtained in the present study was high, an indication that the region is endemic for this infection by WHO classification. This calls for an urgent need for an effective urinary schistosomiasis control programme in the region. Another major concern discovered in the present study was the poor level of awareness of schistosomiasis among the primary school children in the region. Although majority of the pupils identified significant risk factors such as washing of clothes in streams, swimming / drinking contaminated water and playing / bathing in rivers or uncompleted dams that might harbor the intermediate host (Bullinus spp.), an appreciable proportion could still not linked disease causation to any known factor.

In the light of this, sound health education, regular school-based deworming programmes can costeffectively reduced, reverse and prevent morbidity and mortality associated with urinary schistosomiasis in children. In addition, embarking on sustained infrastructure with a skilled workforce that is in close regular contact with the community, environmental sanitation and reduction of human activities that could unnecessarily disturb the ecosystem will go a long way to reduce transmission and prevent reinfection of cases. It is imperative to further conduct a more comprehensive epidemiological survey of urinary schistosomiasis to identify all high risk endemic communities in Ikorodu North Local Government in totality. Also, the need to design strategies to map infection foci as well as the occurrence of the snail intermediate hosts in different contaminated water bodies and its control.

\section{Abbreviations \\ WHO, World Health Organization; UNICEF, United Nations International Children's Emergency Fund.}

\section{Competing interests}

The author declares no competing interest.

\section{Contribution of Author}

OA Olalubi conceived, designed, performed the laboratory analysis and prepared the manuscript.

OB Fagbemi supervised the entire work.

\section{Acknowledgements}

The author wish to thank the community head, head teachers, class teachers, pupils, parents and guardians of Igbokuta village primary schools for their unflinching willingness and support throughout the study period.

Effort of YA Adeyemo, a trained nursing sister for distribution of questionnaire and transfer of samples to the laboratories was highly appreciated.

Lastly, huge appreciation to AE Adewuyi for analyzing and interpreting the data. 


\section{References}

[1]. Chitsulo L, Engels D, Montresor A, Savioli L: The global status of schistosomiasis and its control. Acta Trop 2000,77:41-51.

[2]. Uneke CJ, Egede MU: Impact of Urinary Schistosomiasis on nutritional status of school childen in South-Eastern Nigeria. The Internet Journal of Health 2009, 9 (1)

[3]. Ofoezie IE, Oladejo SO: Unabated schistosomiasis transmission in Erinle River Dam, Osun State, Nigeria: evidence of neglect of environmental effects of development projects. Tropical Medicine and International Health 2006, 11 (6) 843-850

[4]. Odaibo AB, Adewunmi CO, Olorunmola FO: Preliminary Studies on the Prevalence and Distribution of Urinary Schistosomiasis in Ondo State, Nigeria. Afr J Med Sci 2004, 33(3): 219-24.

[5]. Okoli CG, Iwuala MO: The Prevalence, Intensity and Clinical Signs of Urinary Schistosomiasis in Imo state, Nigeria. J Helminthol 2004, 78(4): 337-342.

[6]. Mafiana CF, Ekpo UF, Ojo DA: Urinary Schistosomiasis in Preschool Children in Settlements around Oyan Reservoir in Ogun State, Nigeria: Implications for Control. Trop Med Intl Health 2003, 8(1): 78-82.

[7]. Nduka FO, Etusim PE, Nwaugo VO, Oguariri RM: The Effects of Quarry Mining on the epidemiology of Schistosoma haematobium in schoolchildren, in Ishiagu, South-eastern Nigeria. Ann Trop Med Parasitol 2006, 100(2): $155-161$.

[8]. Ogbe MG, Olojo AO: A preliminary survey of urinary schistosomiasis in Abeokuta, Nigeria. Niger J Basic Appl Sci 1989, 3:158168 .

[9]. Ogbe MG, Ogunsekan FA: Schistosoma haematobium infections among school children in Abeokuta, Nigeria: a preliminary report. Niger J Parasitol 1990, 9-11:60-62.

[10]. Ofoezie IE, Imerbore AMA, Balogun MD, Ogunkoya OO, Asaolu SO: A study of outbreak of schistosomiasis in resettlement villages near Abeokuta, Ogun State, Nigeria. J Helminthol 1991, 25:95-102.

[11]. Mafiana CF, Adesanya OO: Urinary schistosomiasis in Ilewo-orile, Ogun State, Nigeria. Niger J Parasitol 1994, 15:31-34.

[12]. Adeoye GO, Akabogu OAS: Occurrence of urinary schistosomiasis among residents of Ado-Odo/Ota area of Ogun State, Nigeria. Niger J Parasitol 1996, 17:23-30.

[13]. Mafiana CF, Beyioku YO: Schistosoma haematobium infection in Abeokuta, Nigeria. Afr J Med Sci 1998, 27(1-2):5-7.

[14]. Ekpo UF, Mafiana CF: Epidemiology studies of Urinary Schistosomiasis in Ogun State: Identification of high-risk communities. Niger J Parasitol 2004, 25:111-119.

[15]. Akinwale OP, Akpunonu VN, Ajayi M, Akande DO, Adeleke MA, Gyang PV, Adebayo MO, and Dike AA: Urinary schistosomiasis transmission in Epe, an urban community of Southwest Nigeria. Trop Parasitol 2011, 1 (2):99-103.

[16]. Ekpo UF, Laja-Deile A, Oluwole SA, Sammy OS, Mafiana CF: Urinary Schistosomiasis among preschool children in a rural community near Abeokuta, Nigeria. Parasites \& Vectors 2010, 3:58

[17]. Montresor A, Crompton DWT, Hall A, Bundy DAP, Savioli L: Guidelines for the elevation of soil-transmitted helminthiasis and schistosomiasis at community level. World Health Organization Geneva; 1998.

[18]. World Health Organization: Sedimentation Method. Basic Laboratory Methods in Medical Parasitology. World Health Organization Geneva; 1991, 33-35.

[19]. World Health Organization: Manual of Basic Techniques for a Health Laboratory, $2^{\text {nd }}$ Edition. World Health Organization, Geneva, 2003.

[20]. Cheesbrough M: District Laboratory Practice in Tropical Countries. Part 1. Cambridge University Press, London, 1998.

[21]. Samie A, Nchachi DJ, Obi CL, Igumbor EO: Prevalence and temporal distribution of Schistosoma haematobium infections in the Vhembe district, Limpopo Province, South Africa. African Journal of Biotechnology 2010, 42 (9): 7157-7164.

[22]. Tohon ZB, Mainassara HB, Garba A, Mahamane AE, Bosque-Oliva E, Ibrahim ML, Duchemin JB, Chanteau S, Boisier P : Controlling schistosomiasis: significant decrease of anaemia prevalence one year after a single dose of praziquantel in Nigerian school children. PLOS Negl Trop Dis 2: 2008, e241. Doi: 10. 1371/journal. Pntd. 0000241.

[23]. Hamman HM, Zarzour AH, Moftar FM, Abdel-Aty MA, Hany AH, El-Kady AY, Nasr AM, Abd-El-Samie A, Qayed MH, Mikhail NN, Talaat M, Hussein MH: The epidemiology of schistosomiasis in Egypt: Qena governorate. Am J Trop Med Hyg 2000, 62: $80-87$.

[24]. World Health Organization: Prevention and Control of schistosomiasis and soil transmitted helminthiasis. WHO Technical Report Services, Geneva, 2002, 912 (i-vi):1-57.

[25]. Attah DD, Dakul DA, Adamu T, Uneke CJ, Kumbak D: Prevalence of schistosomiasis in the former Zuru Emirate Council, Kebbi State, Nigeria. Nig J Exp Appl Biol 2002, 3:195-199.

[26]. Mafe MA, Appelt B, Adewale B: Effectiveness of different approaches to mass delivery of praziquantel among school-aged children in rural communities in Nigeria. Acta Trop 2005, 93:181-190

[27]. Uneke CJ, Ugwuoru CDC, Ngwu BAF, Ogbu O, Agala CU: Public health implication of bacteriuria and antibiotic susceptibility of bacteria isolates in Schistosomiasis haematobium infected school pupils in South-Eastern Nigeria. World Health Popn 2006, 1-11.

[28]. Kabatereine NB, Brooker S, Tukahebwa EM, Kazibwe F, Onapa AW: Epidemiology and geography of Schistosoma mansoni in Uganda: implications for planning control. Trop Med Int Health 2004, 9: 372-380.

[29]. Sturrock HJW, Picon D, Sabasio A, Oguttu D, Robinson E: Integrated Mapping of Neglected Tropical Diseases: Epidemiological Findings and Control Implications for Northern Bahr-el-Ghazal State, Southern Sudan. PLoS Neg1 Trop Dis 2009, 3: e537.

[30]. World Health Organization Expert Committee on Physical Status: The Use and Interpretation of Anthropometry: report of a WHO expert committee. WHO technical report series $1995,854$.

[31]. Stevenson LS, Latham MC, Kurz KM: Urinary iron loss and physical fitness of Kenyan Children with Urinary Schistosomiasis. Am J Trop Med Hyg 1985, 34(2): 322-330.

[32]. Ekanem EE, Asindi AA, Ejezie GC, Antia-Obong OE: Effect of Schistosoma haematobium infection on the physical growth and school performance of Nigerian children. Cent Afr J Med Hyg 1994, 40(2):38-44.

[33]. McGarvey ST, Wu G, Zhang S: Child growth, nutritional status and Schistosoma japonica in Jiangxi, People's Republic of China. Am J Trop Med Hyg 1993, 48:547-553.

[34]. Parraga IM, Assis AMO, Prado MS: Gender differences in growth of school aged children with schistosomiasis. Am J Trop Med Hyg 1996, 55:150-156.

[35]. Mott KE, Dixon E, Eosel F, England EC: Relation between intensity of Schistosoma haematobium infection and clinical haematuria and proteinuria. Lancet 1983, 1:1005-1006.

[36]. Ndhlovu P, Cadman H, Vennervald BJ, Christensen NO, Chidimu M, Chandiwana SK: Age-related antibody profiles in Schistosoma haematobium infections in a rural community in Zimbabwe. Parasite Immunol 1996, 18:181-191. 